\title{
Neonatal vitamin D status is not associated with later risk of type 1 diabetes: results from two large Danish population-based studies
}

\author{
Ramune Jacobsen $^{1,2}$ - Steffen U. Thorsen ${ }^{3,4}$ • Arieh S. Cohen ${ }^{5}$ Marika Lundqvist ${ }^{5}$ • \\ Peder Frederiksen $^{1}$ - Christian B. Pipper ${ }^{6}$ - Flemming Pociot ${ }^{3,4}$ - Lau C. Thygesen ${ }^{7}$. \\ Alberto Ascherio $^{8}$ • Jannet Svensson ${ }^{3,4}$ • Berit L. Heitmann ${ }^{1,2,7,9,10}$
}

Received: 23 February 2016 / Accepted: 5 May 2016 / Published online: 30 May 2016

(C) Springer-Verlag Berlin Heidelberg 2016

\begin{abstract}
Aims/hypothesis The aim of this work was to assess whether neonatal levels of 25-hydroxyvitamin D $(25(\mathrm{OH}) \mathrm{D})$ are associated with risk of developing type 1 diabetes before the age of 18 years.

Methods Two large-scale studies with different designs - a case-cohort and a case-control-were conducted using Danish national register data and biobank material. Weighted Cox regression and conditional logistic regression were used to calculate $\mathrm{HRs}$ and ORs, respectively. The concentration of $25(\mathrm{OH}) \mathrm{D}$ was assessed from neonatal dried blood spots using highly sensitive liquid chromatography-tandem mass spectrometry. Quintiles of $25(\mathrm{OH}) \mathrm{D}_{3}$ were used in the main analyses.
\end{abstract}

Ramune Jacobsen and Steffen U. Thorsen are joint first authors.

Electronic supplementary material The online version of this article (doi:10.1007/s00125-016-4002-8) contains peer-reviewed but unedited supplementary material, which is available to authorised users.

Ramune Jacobsen

ramune.jacobsen@regionh.dk

1 Research Unit for Dietary Studies at The Parker Institute, Copenhagen University Hospital, Bispebjerg og Frederiksberg, Nordre Fasanvej 57, Hovedvejen, Entrance 5, Ground Floor, 2000 Frederiksberg, Denmark

2 The Institute of Preventive Medicine, Bispebjerg and Frederiksberg Hospital, The Capital Region, Frederiksberg, Denmark

3 Copenhagen Diabetes Research Center (CPH-DIRECT), Department of Paediatrics, Herlev Hospital, University of Copenhagen, Herlev, Denmark

4 Faculty of Health and Medical Sciences, University of Copenhagen, Copenhagen, Denmark
Results The case-cohort study included 912 type 1 diabetes cases and 2866 individuals without type 1 diabetes born in Denmark between 1981 and 2002 and followed up until the end of 2012. The case-control study included 527 matched case-control pairs born between 1981 and 1999 and followed up until May 2004. Both studies found no association between $25(\mathrm{OH}) \mathrm{D}_{3}$ levels and later risk of developing type 1 diabetes. The neonatal total 25(OH)D levels in the studies were low: $46 \%$ (case-cohort study) and $51 \%$ (case-control study) of individuals had 25(OH)D levels $<25 \mathrm{nmol} / \mathrm{l}$.

Conclusions/interpretation Our two large-scale national studies showed that $25(\mathrm{OH}) \mathrm{D}_{3}$ levels around the time of birth were not associated with later type 1 diabetes risk. Whether higher levels of $25(\mathrm{OH}) \mathrm{D}_{3}$ during pregnancy, acquired by higher doses of supplementation than are recommended today in

5 Department of Congenital Disorders, Statens Serum Institute, Copenhagen, Denmark

6 Department of Public Health, Section of Biostatistics, University of Copenhagen, Copenhagen, Denmark

7 National Institute of Public Health, University of Southern Denmark, Copenhagen, Denmark

8 Department of Nutrition, Harvard T. H. Chan School of Public Health, Boston, MA, USA

9 The Boden Institute of Obesity, Nutrition Exercise and Eating Disorders, Charles Perkins Centre, The University of Sydney, Sydney, NSW, Australia

10 Institute of Public Health, University of Copenhagen, Copenhagen, Denmark 
most countries, could protect the offspring against type 1 diabetes cannot be ruled out by the present studies.

Keywords Denmark · Gestation · Registers · Type 1 diabetes $\cdot$ Vitamin D developing type 1 diabetes before the age of 18 years in largescale studies using Danish national register data. We measured $25(\mathrm{OH}) \mathrm{D}$ levels in neonatal dried blood spots (DBS) consisting of capillary blood taken from nearly all neonates in Denmark within a week after birth [12]. Here we report the results of two studies simultaneously conducted by two different research groups.

\section{Methods}

\section{Data sources}

The Danish Civil Registration System (CRS), established in 1968, registers all persons in Denmark alive on 2 April 1968 and born thereafter [13]. The unique personal identification number (CPR) from the CRS can be used for linkage with individual information from a range of other routine administrative registers and large clinical databases in the country. The Danish Childhood Diabetes Registry (DanDiabKids), established in 1996, collects information on all hospitalised incident cases of type 1 diabetes diagnosed at age 15 years and below before 1 January 1996 (i.e. born since 1981); since 2015 individuals diagnosed at up to age 18 years are included [2]. For all cases reported to the DanDiabKids, the original hospital records are scrutinised to establish the validity of the diagnosis. Statistics Denmark (SDK) maintains a large number of national registers including the National Birth Registry, the Family Register, the Population Education Register, the Income Statistics Register, the Immigration and Descendants Register, the Labor Market Register, the Danish Prevention Register and the National Patient Register [14]. Finally, the Danish Newborn Screening Biobank (DNSB) at the Statens Serum Institute (SSI) has stored neonatal DBS at $-20^{\circ} \mathrm{C}\left(-4^{\circ} \mathrm{F}\right)$ since 1 May 1981 [12].

\section{Assessment of vitamin D status}

In both studies, vitamin $\mathrm{D}$ status was assessed by measuring $25(\mathrm{OH}) \mathrm{D}_{2}$ and $25(\mathrm{OH}) \mathrm{D}_{3}$ in $3.2 \mathrm{~mm}$ samples (also called punches) taken from DBS cards. Sample preparation and analysis was performed using liquid chromatography-mass spectrometry (LC-MS) according to a modified version of the analysis [15]. The modifications consisted of calibrations conducted by using commercially available calibrators and controls (Perkin Elmer, Waltham, MA, USA) and an online extraction step. The LC-MS system consisted of an Aria TLX2 system (Thermo Fisher Scientific, Waltham, MA, USA) with two Agilent 1100 binary pumps and two Agilent Quaternary pumps (Agilent, Santa Clara, CA, USA) connected 
to a Thermo TSQ Ultra triple quadrupole mass spectrometer equipped with an electrospray ion source. Online extraction was performed using a Cyclone $\mathrm{P} 0.5 \mathrm{~mm} \times 50 \mathrm{~mm}$ Turbo flow column (Thermo Fisher Scientific) and analytical separation was achieved using Hypersil gold $50 \mathrm{~mm} \times 2.1 \mathrm{~mm}, 3 \mu \mathrm{m}$ reversed-phase column (Thermo Fisher Scientific). To control the quality of the analyses, Perkin Elmer's MSMS Vitamin D kit for mass spectrometry was used. Two sets of controls at three different concentration levels were analysed before and after project samples within each batch. In addition, native full blood from a healthy volunteer was spotted onto filter paper and analysed before and after project samples. All the controls were set to be within $15 \%$ of the target value, otherwise the results were rejected.

The lower limit of quantification (LLOQ) was $4 \mathrm{nmol} / 1$ for $25(\mathrm{OH}) \mathrm{D}_{3}$ and $3 \mathrm{nmol} / 1$ for $25(\mathrm{OH}) \mathrm{D}_{2}$. The $25(\mathrm{OH}) \mathrm{D}$ levels from the DBS are full blood concentrations. Most 25(OH)D molecules in the bloodstream are protein bound and to approximate and report sera concentrations we corrected the original levels using the formula: serum $25(\mathrm{OH}) \mathrm{D}=$ full blood $25(\mathrm{OH}) \mathrm{D} \times(1 /$ $[1-0.61])$, where 0.61 is the haematocrit fraction for capillary blood [16].

a

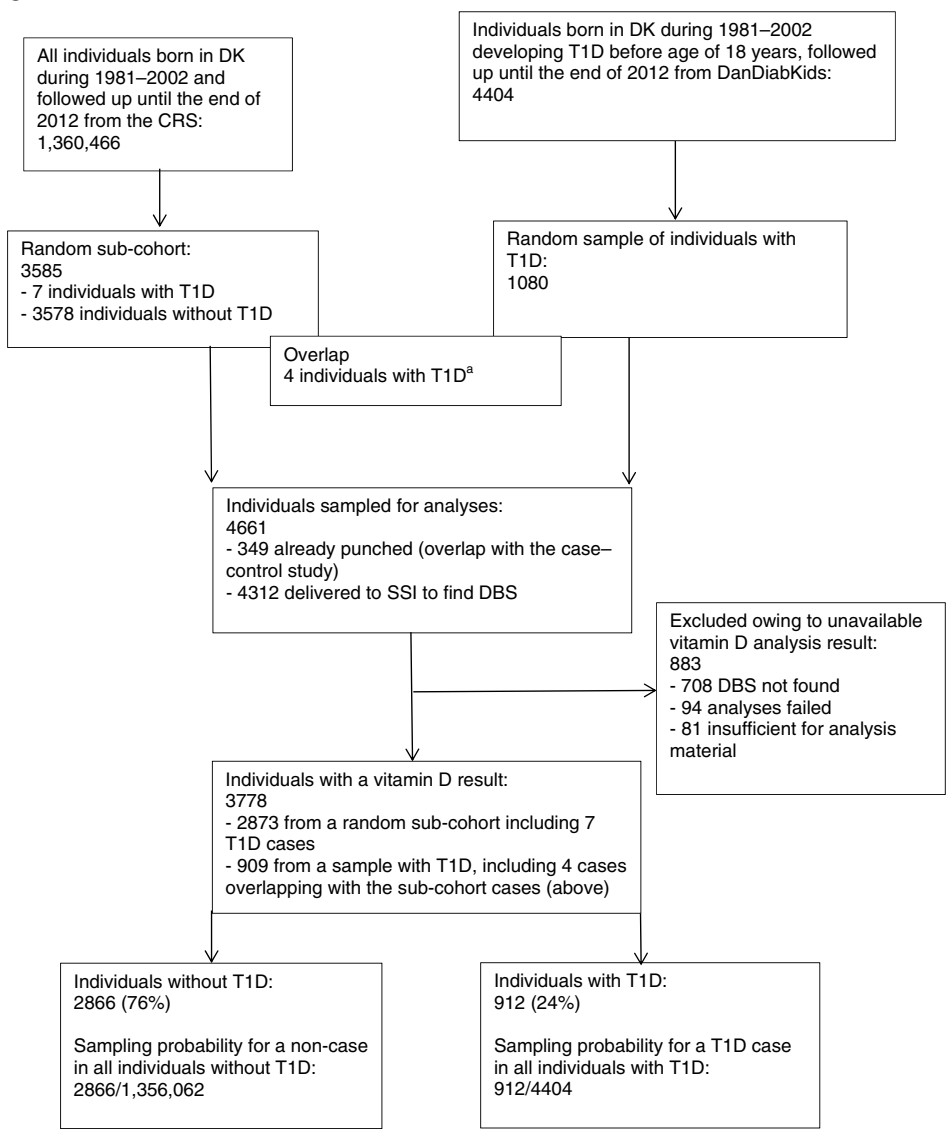

Study design, sample population and variables

Case-cohort study The case-cohort study included a random subcohort of 3585 individuals from the CRS from among $1,360,466$ individuals born in Denmark during 1981-2002, and followed up until the end of 2012; during the follow-up time, seven individuals had developed type 1 diabetes. According to power calculations, $80 \%$ power and a sample size of 1000 cases with type 1 diabetes would show a least detectable HR of 1.15 related to $1 \mathrm{SD}$ difference in $25(\mathrm{OH}) \mathrm{D}$ with $60 \%$ variance explained by all the covariates [17]. As not all DBS cards can be found in the DNSB, we randomly sampled 1080 cases from the DanDiabKids among a total of 4404 in the register born in 1981-2002 and diagnosed until the end of 2012; four of the sampled cases overlapped with the seven type 1 diabetes cases from the random subcohort sample. Inclusion and exclusion criteria are shown in Fig. 1a.

For the 4661 selected individuals, information on birth outcomes, parent's diabetes, maternal ethnicity and parent's socioeconomic position (i.e. education, employment, income, savings) was collected from the SDK registers and linked with the information on 25(OH)D concentrations. The Danish Data Protection Agency gave permission for data retrieval and

\section{b}

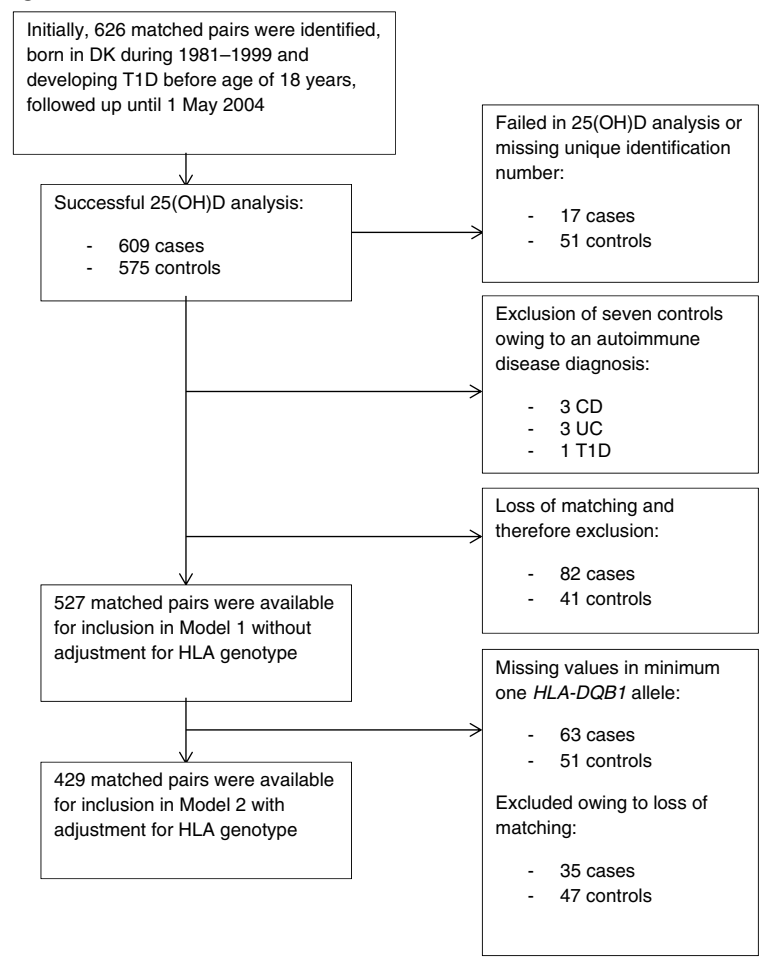

Fig. 1 Flow charts for the case-cohort study (a) and case-control study (b). CD, Crohn's disease; DK, Denmark; T1D, type 1 diabetes; UC, ulcerative colitis. ${ }^{a}$ Allocated to the sub-cohort for descriptive analyses, and to the pool of individuals with T1D for association analyses 
merging (J. no.: 2012-41-41156). Permission to access and analyse the DBS was granted by the Ethical Committee D of the Capital Region of Denmark (J. no.: H-3-2011-126) and the DNSB Steering Committee.

Case-control study The nested case-control study had a 1:1 matching. Power calculation showed that a sample size of 460 matched pairs was needed to demonstrate a decreased risk of $50 \%$; OR was 0.67 for developing type 1 diabetes. Initially, 626 matched pairs were randomly selected for $25(\mathrm{OH}) \mathrm{D}$ analysis from an already-collected material of DBS used in a study conducted by the same research group and originally comprising 2086 cases and 4172 controls [18]. In the original study, type 1 diabetes cases were included if individuals met the following criteria: (1) born between 1981 and 2002; (2) diagnosed between 1 January 1981 and 1 May 2004; (3) had a DBS card present in the DNSB. Individuals were excluded if the following criteria applied: (1) additionally diagnosed with another diabetes type; (2) insufficient material remained on the DBS card; (3) twin, triplet, etc., status (the latter represented 3\% of the cohort). Controls were selected by collecting the DBS card next to the case's card in the DNSB [18], thereby matching on date and therefore season of birth. In the randomly selected sample used in the present study, individuals were born during 1981-1999, due to the fact that $<0.5 \%$ individuals were born during 2000-2002 in the sample of the original study.

Of the 626 selected matched pairs, 527 pairs had complete information on birth outcomes and maternal age and ethnicity, collected from the SDK registers. Additionally, we had information on HLA-DQB1 genotype (HLA risk). Genotyping has been described elsewhere [18] and HLA risk categorisation is shown in Table 1. Inclusion and exclusion criteria are shown in Fig. 1b. The study was approved by the Danish Ethical Committee (H-4-2013-049) and by the DNSB Steering Committee.

\section{Overlap of type 1 diabetes cases between case-cohort and case-control studies}

Both our studies, even though conceived and conducted by two different research groups, used the same national data sources to sample study population. Consequently, 349 cases with type 1 diabetes overlapped between the case-cohort and the case-control study samples. Furthermore, all the punches from DBS cards used in the case-control study were collected already in 2007 , and then stored at $-20^{\circ} \mathrm{C}\left(-4^{\circ} \mathrm{F}\right)$ until recent 25(OH)D analysis [18]. Accordingly, the material used for the analyses in the case-cohort study was mixed in terms of sampling time: the punches from the overlapping 349 cases were collected in 2007 and the remaining punches were newly collected. While running the $25(\mathrm{OH}) \mathrm{D}$ assays, the punches of the 349 overlapping cases were distributed equally throughout all of the microtitre plates and, hence, across different $25(\mathrm{OH}) \mathrm{D}$ analysis times. This approach was used to minimise the risk of confounding between biological and batch effects [19].

\section{Statistical analysis}

As also shown previously [20], a high percentage of the $25(\mathrm{OH}) \mathrm{D}_{2}$ levels were below the LLOQ (3 nmol/l): $91 \%$ in the case-cohort study and $90 \%$ in the case-control study. Therefore, the main analyses reported are for $25(\mathrm{OH}) \mathrm{D}_{3}$ levels. Sensitivity analyses were conducted for total 25(OH)D (i.e. $\left.25(\mathrm{OH}) \mathrm{D}_{3}+25(\mathrm{OH}) \mathrm{D}_{2}\right)$.

Case-cohort study Descriptive data were presented as medians with interquartile range (range between first quartile and third quartile [Q1, Q3]), except for income statistics which were expressed as means (SD). Unlike the classic case-cohort design [21], only a sample of the type 1 diabetes cases from the cohort of all children born between 1981 and 2002 was included in the final analysis. Therefore the analysis was based on sampling theory: to estimate the magnitude of effect of $25(\mathrm{OH}) \mathrm{D}_{3}$ levels on the risk of type 1 diabetes, we used Cox regression with the cases and non-cases in the final sample weighted by their inverse sampling probabilities [22]. The standard errors of the estimated effects were computed by the robust method [23]. Sampling probabilities for individuals with and without type 1 diabetes are shown in Fig. 1a. To better capture a potential non-linear association, the $25(\mathrm{OH}) \mathrm{D}_{3}$ levels were divided into quintiles based on the concentrations of the random subcohort representing general population levels. The regression model was pre-defined based on literature and included the following confounders: gestational and mother's delivery ages, birthweight, mother's ethnicity and history of diabetes and parental socioeconomic position at the time of an individual offspring's birth [24, 25]. Additionally, the model was adjusted for previously reported birth cohort effect in type 1 diabetes incidence increase in Denmark, expressed as a linear variable of year of birth [26]. For sensitivity reasons, analyses were conducted additionally including season in the models, coded as spring (MarchMay), summer (June-August), autumn (SeptemberNovember) and winter (December-February), and using season-specific cut-offs for $25(\mathrm{OH}) \mathrm{D}_{3}$ quintiles [27]. Further sensitivity analyses were conducted in groups with $25(\mathrm{OH}) \mathrm{D}_{3}$ levels below and above $25 \mathrm{nmol} / \mathrm{l}$, as well as in the groups of type 1 diabetes incidence age below and above 5 years. Possible interactions between $25(\mathrm{OH}) \mathrm{D}_{3}$ quintiles and sex (Wald test) were examined. Descriptive statistics was calculated in SPSS Version 22 (IBM Corporation, New York, NY, USA); regression models were run in Stata Version 14 (StataCorp, College Station, TX, USA). 
Table 1 Characteristics of the population in the two studies

\begin{tabular}{|c|c|c|c|c|c|c|}
\hline \multirow[t]{2}{*}{ Variable } & \multicolumn{3}{|c|}{ Case-cohort study } & \multicolumn{3}{|c|}{ Case-control study } \\
\hline & Case & Cohort $^{\mathrm{a}}$ & $p$ value $^{\mathrm{b}}$ & Case & Control & $p$ value $^{\mathrm{b}}$ \\
\hline \multicolumn{7}{|l|}{ Variable of main interest } \\
\hline 25(OH)D level & & & 0.24 & & & 0.61 \\
\hline Median, nmol/1 & 26.9 & 26.8 & & 24.7 & 24.8 & \\
\hline $\mathrm{Q} 1, \mathrm{Q} 3, \mathrm{nmol} / \mathrm{l}$ & $17.8,41.3$ & $16.5,39.7$ & & $15.7,36.6$ & $15.7,35.4$ & \\
\hline$n$ & 912 & 2873 & & 527 & 527 & \\
\hline$\%$ with levels above $50 \mathrm{nmol} / 1$ & 14.8 & 13.5 & & 10.3 & 9.6 & \\
\hline$\%$ with levels below $25 \mathrm{nmol} / 1$ & 45.5 & 45.6 & & 51.2 & 51.0 & \\
\hline $25(\mathrm{OH}) \mathrm{D}_{3}$ level & & & 0.08 & & & 0.51 \\
\hline Median, nmol/1 & 24.3 & 23.8 & & 21.3 & 21.1 & \\
\hline $\mathrm{Q} 1, \mathrm{Q} 3, \mathrm{nmol} / \mathrm{l}$ & $14.8,38.8$ & $13.5,36.7$ & & $12.5,33.1$ & $12.0,32.9$ & \\
\hline$n$ & 912 & 2873 & & 527 & 527 & \\
\hline $25(\mathrm{OH}) \mathrm{D}_{3}$ level & & & 0.38 & & & 0.83 \\
\hline Median, nmol/1 & 1.5 & 1.3 & & 1.9 & 1.9 & \\
\hline $\mathrm{Q} 1, \mathrm{Q} 3, \mathrm{nmol} / \mathrm{l}$ & $0.0,3.7$ & $0.0,3.8$ & & $0.0,5.0$ & $0.0,5.0$ & \\
\hline$n$ & 912 & 2873 & & 527 & 527 & \\
\hline \multicolumn{7}{|l|}{ Basic characteristics } \\
\hline Sex & & & 0.24 & & & 0.20 \\
\hline Female, \% & 50.5 & 48.4 & & 49.7 & 45.7 & \\
\hline Male, $\%$ & 49.5 & 51.6 & & 50.3 & 54.3 & \\
\hline$n$ & 912 & 2873 & & 527 & 527 & \\
\hline Age of onset & & & 0.59 & & & NA \\
\hline Median, years & 10.2 & 10.5 & & 8.5 & - & \\
\hline Q1, Q3, years & $7.5,12.5$ & $5.1,11.5$ & & $5.0,11.4$ & - & \\
\hline$n$ & 912 & 7 & & 527 & - & \\
\hline Mother's age at child's birth & & & 0.04 & & & 0.14 \\
\hline Median, years & 28 & 28 & & 28 & 27 & \\
\hline Q1, Q3, years & 26,32 & 25,32 & & 25,31 & 24,31 & \\
\hline$n$ & 912 & 2833 & & 527 & 527 & \\
\hline \multicolumn{7}{|l|}{ Pregnancy and birth } \\
\hline Gestational age & & & 0.002 & & & 0.94 \\
\hline Median, weeks & 40 & 40 & & 40 & 40 & \\
\hline Q1, Q3, weeks & 39,41 & 39,41 & & 39,41 & 39,40 & \\
\hline$n$ & 907 & 2815 & & 527 & 527 & \\
\hline Birthweight & & & 0.88 & & & 0.11 \\
\hline Median, kg & 3.5 & 3.5 & & 3.5 & 3.5 & \\
\hline Q1, Q3, kg & $3.2,3.9$ & $3.2,3.9$ & & $3.2,3.9$ & $3.1,3.8$ & \\
\hline$n$ & 911 & 2824 & & 527 & 527 & \\
\hline \multicolumn{7}{|l|}{ Ethnicity } \\
\hline Mother's ethnicity & & & $<0.00$ & & & 0.36 \\
\hline Danish, \% & 94.6 & 90.5 & & 96.8 & 95.2 & \\
\hline Other western, \% & 1.9 & 2.3 & & 0.4 & 1.0 & \\
\hline Other non-western, \% & 3.5 & 7.2 & & 2.8 & 3.8 & \\
\hline$n$ & 912 & 2850 & & 527 & 527 & \\
\hline \multicolumn{7}{|l|}{ Genetics } \\
\hline HLA risk groups & & & NA & & & $<0.00$ \\
\hline $\operatorname{High}^{\mathrm{c}}, \%$ & - & - & & 63.9 & 15.6 & \\
\hline Moderate $^{\mathrm{d}}, \%$ & - & - & & 21.2 & 25.6 & \\
\hline Low/protective ${ }^{\mathrm{e}}, \%$ & - & - & & 14.9 & 58.8 & \\
\hline$n$ & - & - & & 429 & 429 & \\
\hline Mother's diabetes ${ }^{\mathrm{f}}$ & & & 0.003 & & & NA \\
\hline Yes, \% & 6.8 & 4.4 & & - & - & \\
\hline No, $\%$ & 93.2 & 95.6 & & - & - & \\
\hline$n$ & 912 & 2873 & & - & - & \\
\hline Father's diabetes ${ }^{\mathrm{f}}$ & & & & & & NA \\
\hline Yes, \% & 4.6 & 0.2 & & - & - & \\
\hline No, $\%$ & 95.4 & 99.8 & & - & - & \\
\hline$n$ & 912 & 2873 & & - & - & \\
\hline \multicolumn{7}{|l|}{ Socioeconomic status } \\
\hline Mother's education ${ }^{\mathrm{g}}$ & & & 0.06 & & & NA \\
\hline Elementary school, \% & 27.5 & 30.8 & & - & - & \\
\hline Gymnasium/professional, \% & 49.5 & 47.7 & & - & - & \\
\hline University, $\%$ & 23.1 & 21.4 & & - & - & \\
\hline$n$ & 885 & 2746 & & - & - & \\
\hline
\end{tabular}


Table 1 (continued)

\begin{tabular}{|c|c|c|c|c|c|c|}
\hline \multirow[t]{2}{*}{ Variable } & \multicolumn{3}{|c|}{ Case-cohort study } & \multicolumn{3}{|c|}{ Case-control study } \\
\hline & Case & Cohort $^{\mathrm{a}}$ & $p$ value $^{\mathrm{b}}$ & Case & Control & $p$ value $^{\mathrm{b}}$ \\
\hline Mother's job status ${ }^{\mathrm{g}}$ & & & $<0.00$ & & & NA \\
\hline Employed, \% & 77.1 & 73.5 & & - & - & \\
\hline Unemployed, \% & 9.0 & 11.5 & & - & - & \\
\hline Out of labour market, \% & 13.8 & 15.0 & & - & - & \\
\hline$n$ & 910 & 2802 & & - & - & \\
\hline Father's job status ${ }^{\mathrm{g}}$ & & & $<0.00$ & & & NA \\
\hline Employed, \% & 93.0 & 89.4 & & - & - & \\
\hline Unemployed, \% & 3.1 & 5.2 & & - & - & \\
\hline Out of labour market, $\%$ & 3.9 & 5.4 & & - & - & \\
\hline$n$ & 901 & 2788 & & - & _- & \\
\hline Mother's gross income $\mathrm{e}^{\mathrm{h}, \mathrm{i}}$ & & & $<0.00$ & & & NA \\
\hline Mean, DKK ${ }^{\mathrm{h}}$ per year & 90,853 & 84,387 & & - & - & \\
\hline $\mathrm{SD}, \mathrm{DKK}^{\mathrm{h}}$ per year & 40,104 & 41,395 & & - & - & \\
\hline$n$ & 912 & 2845 & & - & - & \\
\hline Father's gross income $\mathrm{h}^{\mathrm{h}, \mathrm{i}}$ & & & 0.001 & & & NA \\
\hline Mean, $\mathrm{DKK}^{\mathrm{j}}$ per year & 144,023 & 133,959 & & - & - & \\
\hline $\mathrm{SD}, \mathrm{DKK}^{\mathrm{j}}$ per year & 109,218 & 7520 & & - & - & \\
\hline$n$ & 907 & 2845 & & _ & _- & \\
\hline Mother's income from savings $\mathrm{h}$ & & & 0.01 & & & NA \\
\hline Mean, $\mathrm{DKK}^{\mathrm{j}}$ per year & 3732 & 3529 & & _- & _- & \\
\hline $\mathrm{SD}, \mathrm{DKK}^{\mathrm{j}}$ per year & 5538 & 6851 & & _- & _- & \\
\hline$n$ & 912 & 2845 & & - & _- & \\
\hline Father's income from savings ${ }^{\mathrm{h}}$ & & & 0.08 & & & NA \\
\hline Mean, $\mathrm{DKK}^{\mathrm{j}}$ per year & 7152 & 6920 & & - & - & \\
\hline $\mathrm{SD}, \mathrm{DKK}^{\mathrm{j}}$ per year & 16,356 & 34,145 & & - & - & \\
\hline$n$ & 907 & 2814 & & - & - & \\
\hline
\end{tabular}

The case-control study was based on 527 matched pairs, although the $H L A-D Q B 1$ risk grouping was calculated using the 429 matched pairs with both alleles genotyped

${ }^{a}$ Descriptive characteristics for all subcohort individuals, including seven cases with type 1 diabetes

${ }^{\mathrm{b}}$ When making a comparison in the case-cohort study, the overlap of four individuals between subcohort and type 1 diabetes sample was allocated to the subcohort; statistical tests used in both studies: $\chi^{2}$ test for categorical variables and Mann-Whitney $U$ test for numerical variables

${ }^{\mathrm{c}} H L A-D Q B 1$ *allele_1/*allele_2: 03:02/99:99, 03:02/02, 06:04/03:02

${ }^{\mathrm{d}} H L A-D Q B 1 *$ allele_1/*allele_2: 03:01/02, 06:03/03:02, 02/99:99, 06:04/02, 06:04/99:99, 03:01/03:02. 06:04/03:04

${ }^{\text {e } H L A-D Q B 1}$ *allele_1/*allele_2: 06:02/03:02, 06:02/99:99, 06:02/02, 06:03/99:99, 03:01/99:99, 06:02/03:01, 06:03/03:01, 06:04/03:01, 06:03/02, 03:04/99:99, 03:04/02, 06:02/03:04, 99:99/99:99 (99:99= remaining alleles)

${ }^{\mathrm{f}}$ All diabetes diagnoses, excluding gestational, given in a hospital setting before the individual's birth

${ }^{\mathrm{g}}$ On 1 January in the year of the offspring's birth

${ }^{\text {h }}$ On 1 January in the year of the offspring's birth, adjusted for year 1981 prices/inflation

${ }^{\mathrm{i}}$ Income including pension and taxes

${ }^{\mathrm{j}} 1$ Danish krone $(\mathrm{DKK})=0.13$ Euro or 0.15 US dollars

Case-control study Descriptive data were expressed as median $(\mathrm{Q} 1, \mathrm{Q} 3)$ and the measure of effect was OR including 95\% CI. Univariate and multivariate conditional logistic regression analyses were performed to examine the influence of $25(\mathrm{OH}) \mathrm{D}_{3}$ on odds of developing type 1 diabetes adjusted for possible confounders. $25(\mathrm{OH}) \mathrm{D}_{3}$ was modelled as a continuous variable and to capture a possible non-linear relationship between $25(\mathrm{OH}) \mathrm{D}_{3}$ levels and type 1 diabetes risk, we used quintiles based on the whole sample population. The assumptions for logistic regression were fulfilled. As in the case-cohort study, the models were based on pre-defined literature-based hypothesised associations between a confounder, $25(\mathrm{OH}) \mathrm{D}_{3}$ levels and type 1 diabetes risk. The following confounders were included: gestational and mother's delivery age, birthweight and mother's ethnicity [24, 25]. Two adjusted models were generated - one with and one without the HLA risk variable (Fig. 2). Sensitivity analyses and interactions were conducted as described under the case-cohort study. In addition, an interaction between $25(\mathrm{OH}) \mathrm{D}_{3}$ quintiles and HLA risk was also thought biologically plausible and was therefore examined. All analyses were performed using SAS Version 9.2 (SAS Institute, Cary, NC, USA). 


\section{Results}

In the case-cohort study, the median (Q1, Q3) for $25(\mathrm{OH}) \mathrm{D}_{3}$ was $23.8(15.5,36.7) \mathrm{nmol} / 1$ in individuals from the subcohort and $24.3(14.8,38.8) \mathrm{nmol} / \mathrm{l}$ in cases with type 1 diabetes. In the case-control study, the values were $21.1(12.0,32.9) \mathrm{nmol} / \mathrm{l}$ for controls and $21.3(12.5,33.1) \mathrm{nmol} / 1$ for cases. Total $25(\mathrm{OH}) \mathrm{D}$, $25(\mathrm{OH}) \mathrm{D}_{3}$ and $25(\mathrm{OH}) \mathrm{D}_{2}$ levels did not differ between the subcohort and cases or between the controls and cases in the respective studies. Notably, 91\% of $25(\mathrm{OH}) \mathrm{D}_{2}$ and $15 \%$ of $25(\mathrm{OH}) \mathrm{D}_{3}$ concentrations were below the LLOQ in the case-cohort study; respective values in the case-control study were $90 \%$ and $19 \%$. A trend of a slight increase in $25(\mathrm{OH}) \mathrm{D}_{3}$ concentrations over years was observed in the case-cohort study: $\beta(95 \% \mathrm{CI})=0.02(0.00,0.04), p<0.001 \quad(\mathrm{ESM}$
Fig. 1). All the characteristics of the sample population in both studies are presented in Table 1 .

\section{Case-cohort study}

We found no association between the quintiles of $25(\mathrm{OH}) \mathrm{D}_{3}$ concentrations and type 1 diabetes risk either in the main adjusted analysis (Fig. 2) or in any of the sensitivity analyses (data not shown). The interaction between sex and $25(\mathrm{OH}) \mathrm{D}_{3}$ quintiles was not significant. Additionally, we found that gestational age (per week) (HR [95\% CI] 0.96 [0.93, 1.00]), mother's diabetes status (diabetes vs no diabetes) (1.67 $[1.20,2.33])$ and ethnicity (non-western vs Danish) (0.39 $[0.25,0.61])$ were associated with type 1 diabetes risk. As expected, birth cohort effect showed an increase in type 1 diabetes incidence over years (Fig. 2).
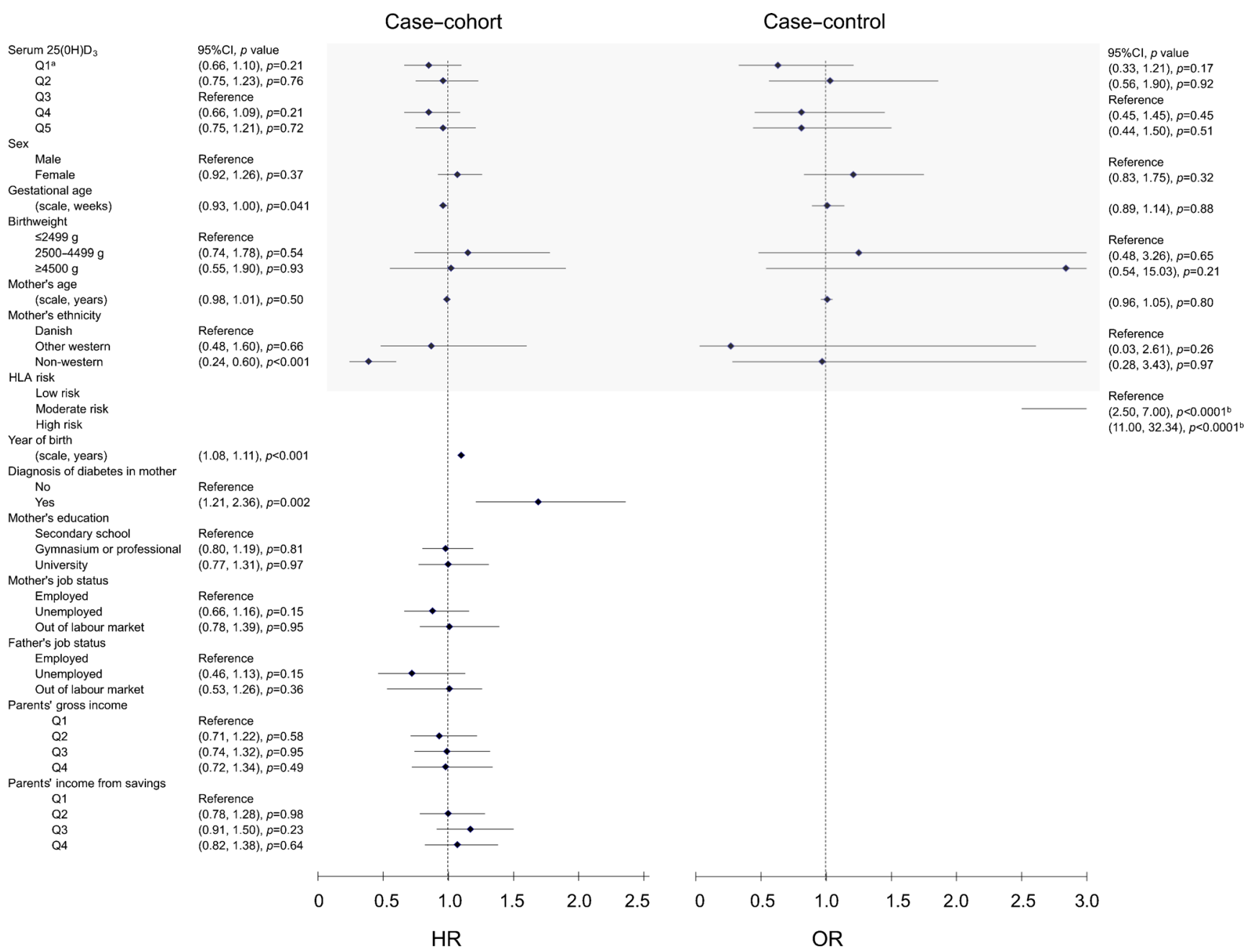

Fig. 2 Association between the quintiles of $25(\mathrm{OH}) \mathrm{D}_{3}$ concentrations and type 1 diabetes risk. ${ }^{a}$ Quintile values for $25(\mathrm{OH}) \mathrm{D}_{3}(\mathrm{nmol} / 1)$ in the case-cohort study were as follows: first quintile (Q1) 0-11.92; second quintile (Q2) 11.92-19.58; third quintile (Q3) 19.58-28; fourth quintile (Q4) 28-40.79 and fifth quintile (Q5) 40.79-130.34. Quintile values for
$25(\mathrm{OH}) \mathrm{D}_{3}(\mathrm{nmol} / \mathrm{l})$ in the case-control study were as follows: Q1 0 10.62; Q2 10.62-17.35; Q3 17.35-25.25; Q4 25.25-36.10 and Q5 $36.10-117.91$. ${ }^{\mathrm{O}} \mathrm{OR}$ estimate and $95 \%$ CIs are outside range of visualisation. The shaded grey area captures the overlap of variables between the two studies 


\section{Case-control study}

We found no association between $25(\mathrm{OH}) \mathrm{D}_{3}$ around time of birth and type 1 diabetes risk in the adjusted models, either when modelling $25(\mathrm{OH}) \mathrm{D}_{3}$ as a continuous variable in model 1 (excluding HLA risk: OR [95\% CI] [per $25 \mathrm{nmol} / 1$ increase] $1.02[0.80,1.28]$ ) and model 2 (including HLA risk: OR [95\% $\mathrm{CI}]$ [per $25 \mathrm{nmol} / \mathrm{l}$ increase] $0.86[0.60,1.22])$ or when quintiles were used (Fig. 2). Sensitivity analyses yielded essentially identical results (data not shown). Interactions between sex, HLA risk and $25(\mathrm{OH}) \mathrm{D}_{3}$ quintiles were not significant (data not shown). Additionally, HLA risk was significantly associated with type 1 diabetes risk. A birthweight below $2500 \mathrm{~g}$ was related to a decreased risk of type 1 diabetes when compared with a birthweight of $2500-4499 \mathrm{~g}$, but this association was only seen in model 1 (excluding HLA risk).

\section{Discussion}

The present study examined relations between neonatal $25(\mathrm{OH}) \mathrm{D}_{3}$ levels and the risk of developing type 1 diabetes before the age of 18 years. We did not observe an association in either of two large-scale studies, using measured neonatal $25(\mathrm{OH}) \mathrm{D}_{3}$ levels and validated complete registry-based diagnosis of type 1 diabetes. While several of the previous studies in this field relied on maternal self-reported dietary intake of vitamin $\mathrm{D}$, or on vitamin $\mathrm{D}$ supplementation during pregnancy $[8,11]$, only two studies so far have examined maternal serum $25(\mathrm{OH}) \mathrm{D}$ concentrations $[9,10]$ and one study looked at the $25(\mathrm{OH}) \mathrm{D}_{3}$ levels in neonatal blood from DBS [7]. Results from these three studies were conflicting: two found, like us, no support for an association [7,9] and one found that lower maternal levels of serum $25(\mathrm{OH}) \mathrm{D}$, measured late in the third trimester, were associated with an increased risk of developing type 1 diabetes in the offspring [10]. The three previous studies were all case-control studies. Importantly, our studies were large-scaled and population-based with limited influence of selection bias possible in the other Nordic studies [9, 10]. Similarly to the other studies, we used a validated and complete registry for type 1 diabetes diagnosis, as well as a validated and reliable 25(OH)D assay. For comparison, the basic information from all previous studies is presented in Table 2.

The neonatal screening samples that were used in our studies showed notably lower 25(OH)D concentrations compared with the levels found in other Nordic studies based on maternal serum $[9,10]$. This is in accordance with the results of the studies comparing $25(\mathrm{OH}) \mathrm{D}_{3}$ levels in pregnant women and in cord blood $[5,28]$. The Norwegian study reported a $25(\mathrm{OH}) \mathrm{D}$ maternal mean level of $41 \mathrm{nmol} / \mathrm{l} \mathrm{vs}$ cord blood mean level of $31 \mathrm{nmol} / 1$ [28] and the Dutch study reported a 25(OH)D maternal mean level of $51 \mathrm{nmol} / 1$ vs cord blood mean level of $32 \mathrm{nmol} / \mathrm{l}$ [5]. Further, we assayed levels in DBS, while the
Norwegian [10] and Finnish [9] studies assayed levels in serum. The latter has 'traceable standards' from the National Institute of Standards and Technology, while assays using DBS rely on a range of other methods to calibrate for accuracy, and there is no reference material or gold standard method to assess the validity of the values from DBS sample analyses [16]. Despite the differences in assay techniques, 25(OH)D concentrations from DBS assays have been shown to correlate with those using cord blood [16] and plasma [29] if the correction for haematocrit fraction is used, as was done in our studies. Thus, we have no reason to believe that the ranking of individuals with respect to neonatal 25(OH)D levels in our studies was compromised.

We also compared $25(\mathrm{OH}) \mathrm{D}_{3}$ concentrations in our studies with those reported by McGrath et al, measured from DBS in the Danish population-based sample comprising 848 individuals born in 1981-1994 [20]. The $25(\mathrm{OH}) \mathrm{D}_{3}$ concentrations reported in the study by McGrath et al were slightly higher than in our studies: median (Q1, Q3) was $32.3(20.5,46.6)$. Notably, the assays referred to by McGrath et al were run in another laboratory, where the extraction and derivatisation techniques were the same. The main difference was that $\mathrm{McGrath}$ et al prepared calibrators through standard addition to native whole blood, whereas our studies were based on purchased calibrators from a commercial vendor. The difference in calibrators may lead to a systematic difference in absolute levels but this, if true, would not interfere with the reliability of the results on reported associations. Moreover, while comparing the $25(\mathrm{OH}) \mathrm{D}_{3}$ results coming from different analysis settings, total variation in the entire analysis sample should be considered. Total variation in the analyses of our entire sample, including the samples from both studies, was $15 \%$. Thus, the $25(\mathrm{OH}) \mathrm{D}_{3}$ levels in our studies differed from those reported by McGrath et al only by a few $\mathrm{nmol} / \mathrm{l}$ (i.e. $25 / 27 \mathrm{nmol} / 1 \pm 15 \%$ ), which is acceptable taking into account different calibration methods.

Considering biochemical aspects, the $25(\mathrm{OH}) \mathrm{D}$ concentrations reported in the Norwegian study [10] still seem to be higher than those found in our studies and in the Finnish study [9]. This corresponds with the findings from previous largescale studies on 25(OH)D concentrations in pregnant women in Nordic countries. The Norwegian Mother and Child Cohort Study found a 25(OH)D mean level of $74 \mathrm{nmol} / 1$ in midpregnancy [30] whereas the Danish Odense Child Cohort study revealed a median mid-pregnancy level of $66 \mathrm{nmol} / \mathrm{l}$ [31]. The use of cod-liver oil by pregnant women in Norway [32] could potentially contribute to the observed relatively higher 25(OH)D levels. Consequently, the difference in findings between our study and that of Miettinen et al [9] vs Sørensen et al [10] may be due to a difference in 25(OH)D concentrations in the studied populations. This further suggests that higher levels of $25(\mathrm{OH}) \mathrm{D}$ are necessary to exert a protective effect against type 1 diabetes in a complex exposure network and that the higher levels may be potentially reached by supplementation. Similarly, Hypponen et al [33] showed 
Table 2 Main information from the studies assessing association between pregnancy or neonatal 25(OH)D levels and risk of type 1 diabetes

\begin{tabular}{|c|c|c|c|c|c|}
\hline Variable & $\begin{array}{l}\text { Sørensen et al } 2012 \\
\text { (Norway) [10] }\end{array}$ & $\begin{array}{l}\text { Miettinen et al } 2012 \\
\text { (Finland) [9] }\end{array}$ & $\begin{array}{l}\text { Cadario et al } \\
2015 \text { (Italy) [7] }\end{array}$ & $\begin{array}{l}\text { Case-cohort, } \\
2016 \text { (Denmark) }\end{array}$ & $\begin{array}{l}\text { Case-control, } \\
2016 \text { (Denmark) }\end{array}$ \\
\hline 25(OH)D measurement, timing & $\begin{array}{l}\text { Serum, pregnancy } \\
\text { third trimester }\end{array}$ & $\begin{array}{l}\text { Serum, pregnancy } \\
\text { first trimester }\end{array}$ & $\begin{array}{l}\text { Neonatal, } \\
\text { third day }\end{array}$ & $\begin{array}{l}\text { Neonatal, } \\
\text { first-third day }\end{array}$ & $\begin{array}{l}\text { Neonatal, first- } \\
\text { third day }\end{array}$ \\
\hline \multicolumn{6}{|l|}{ Population size } \\
\hline Cases & 109 & 343 & 67 & 912 & 527 \\
\hline Controls or cohort & 209 & 343 & 236 & 2873 & 527 \\
\hline Sampling & $\begin{array}{l}\text { National cohort, women } \\
\text { who gave consent }\end{array}$ & $\begin{array}{l}\text { Register based, women } \\
\text { who accepted invitations }\end{array}$ & $\begin{array}{l}\text { Register based, } \\
\text { random } \\
\text { sample }\end{array}$ & $\begin{array}{l}\text { Register based, } \\
\text { random } \\
\text { sample }\end{array}$ & $\begin{array}{l}\text { Register based, } \\
\text { random } \\
\text { sample }\end{array}$ \\
\hline \multicolumn{6}{|l|}{$\begin{array}{l}\text { Serum } 25(\mathrm{OH}) \mathrm{D} \text {, mean }(\mathrm{SD}) \\
\quad \text { or median }(\mathrm{Q} 1, \mathrm{Q} 3)\end{array}$} \\
\hline $\begin{array}{l}\text { Offspring or individuals } \\
\text { with T1D }\end{array}$ & $65.8(26.5)$ & $43.9(16.9)$ & - & $26.9(17.8,41.3)$ & $24.8(15.7,35.4)$ \\
\hline $\begin{array}{l}\text { Offspring or individuals } \\
\text { without T1D }\end{array}$ & $73.1(27.2)$ & $43.5(16.6)$ & - & $26.8(16.5,36.7)$ & $21.1(12.0,32.9)$ \\
\hline \multicolumn{6}{|l|}{$\begin{array}{l}\text { Serum } 25(\mathrm{OH}) \mathrm{D}_{3} \text {, geometrical } \\
\text { mean }^{\mathrm{a}} \text { or median }(\mathrm{Q} 1, \mathrm{Q} 3)\end{array}$} \\
\hline $\begin{array}{l}\text { Offspring or individuals } \\
\text { with T1D }\end{array}$ & - & - & 1.42 & $24.3(14.8,38.8)$ & $21.3(12.5,33.1)$ \\
\hline $\begin{array}{l}\text { Offspring or individuals } \\
\text { without T1D }\end{array}$ & - & - & 1.81 & $23.8(13.5,36.7)$ & $21.1(12.0,32.9)$ \\
\hline T1D cases' year of birth & 1992-1994 & $1993-2000$ & 1992-2012 & 1981-2002 & 1981-1999 \\
\hline T1D incidence periods & 1992-2009 & 1993-2007 & 2002-2012 & 1981-2012 & $1981-2004$ \\
\hline \multicolumn{6}{|l|}{ T1D incidence age in years } \\
\hline Mean or mean (SD) & $9.0(3.6)$ & 3.4 & $4.2(3.4)$ & - & - \\
\hline Median (Q1, Q3) & - & - & - & $10.2(7.5,12.5)$ & $8.5(5.0,11.4)$ \\
\hline Range & $0-15$ & $0-7$ & $0-10$ & $0-18$ & $0-18$ \\
\hline $\begin{array}{l}\text { Association between 25(OH)D } \\
\text { and T1D risk, OR } \\
\text { (95\% CI), adjusted Q1 vs Q4 }\end{array}$ & $2.38(1.12,5.07)$ & NS & NS & NS & NS \\
\hline
\end{tabular}

T1D, type 1 diabetes; Q4, fourth quartile; NS not significant association

${ }^{a}$ Geometrical means in our studies was in the range of 1.1

that high-dose vitamin D supplementation (up to $50 \mu \mathrm{g}$ daily) in infancy reduced type 1 diabetes risk later in life by $80 \%$.

Despite the possibly higher 25(OH)D levels in pregnant women in Norway, type 1 diabetes incidence rates in Norway are higher than in Denmark: 23-33 per 100,000 person-years vs 20-22 per 100,000 person-years, respectively [2, 34]. Clearly, type 1 diabetes is a multifactorial disease and variations in incidence rates between different countries are caused by several factors. In the case-cohort study, maternal diabetes diagnosis, ethnicity and gestational age were associated with type 1 diabetes risk. A lower risk with increasing gestational age has been also reported previously [24]. The increased risk for those with diabetes in first-degree relatives has been reported previously as well [3]. Type 1 diabetes risk in the offspring of mothers with a non-western minority background was lower, despite lower levels of neonatal $25(\mathrm{OH}) \mathrm{D}$. The only consistent association in the case-control study was between HLA risk group and type 1 diabetes risk, as shown previously using the same material [18].
A child with a high load of type 1 diabetes susceptibility genes may be more vulnerable to low levels of $25(\mathrm{OH}) \mathrm{D}$ than a child with a neutral or protective genotype. In the case-cohort study, to consider genetic susceptibility, we made an attempt to adjust for maternal and paternal type 1 diabetes status, which accounts for both HLA and nonHLA risk genes. Maternal diabetes status was shown to be an important predictor of type 1 diabetes hazard in the offspring but it did not change the association between disease risk and neonatal $25(\mathrm{OH}) \mathrm{D}_{3}$ levels. The number of individuals whose fathers had diabetes was too low to provide meaningful results. In the case-control study, adjusting for HLA risk did not change the results either and the case-control study was the first and so far the only study adjusting for HLA risk in the neonatal $25(\mathrm{OH}) \mathrm{D}_{3}$ and type 1 diabetes risk association. The case-control study was unable to adjust for non-HLA genetic susceptibility, which would require a very large sample size due to small effects by these numerous gene variants [3]. 
Interestingly, a tendency towards yearly increase in $25(\mathrm{OH}) \mathrm{D}_{3}$ levels was observed in the case-cohort study (ESM Fig. 1). The observed increase in $25(\mathrm{OH}) \mathrm{D}_{3}$ concentrations may have been caused by an increase in the number of hours of sunshine in Denmark [35] and/or by an increase in vitamin $\mathrm{D}$ intake through supplementation possibly due to a change in vitamin D-related awareness in the public. Additionally, decreased prevalence of smoking (negatively affecting 25(OH)D concentrations [36]) among pregnant women in Denmark may have contributed to the observed differences. On the other hand, due to the wide distribution of values throughout the years, the observed trend in $25(\mathrm{OH}) \mathrm{D}_{3}$ increase may be a spurious result. To take into account the possibility of $25(\mathrm{OH}) \mathrm{D}$ changes over years (and simultaneously consider increase in type 1 diabetes incidence rates over years in Denmark), all the analyses in the casecohort study were adjusted for year of birth expressed as a linear variable.

Our studies were based on hypotheses of gestational programming, in this particular case claiming that low levels of 25(OH)D during periods of immune system maturation may cause long-term irreversible effects on immunological health [37]. It can be argued that one $25(\mathrm{OH}) \mathrm{D}$ measurement at a specific time-point (i.e. at birth) may not mirror earlier $25(\mathrm{OH}) \mathrm{D}$ pregnancy levels. Because the fetus is completely dependent on maternal 25(OH)D supply [38] and because the half-life of $25(\mathrm{OH}) \mathrm{D}$ is approximately $2-3$ weeks [39], the $25(\mathrm{OH}) \mathrm{D}$ levels at birth, as a minimum, reflects fetal $25(\mathrm{OH}) \mathrm{D}$ exposure during the end of third trimester of pregnancy. At the same time, immune maturation is especially prominent with regards to development of self-tolerance from mid-pregnancy [40].

In conclusion, our two nationwide large-scale studies showed that $25(\mathrm{OH}) \mathrm{D}_{3}$ levels around the time of birth were not associated with type 1 diabetes risk. We cannot rule out whether higher levels of $25(\mathrm{OH}) \mathrm{D}_{3}$ during pregnancy, acquired by higher doses of supplementation than those recommended in Nordic countries today ( $10 \mu \mathrm{g}$ daily), may protect the offspring against type 1 diabetes. Likewise, the possibility that $25(\mathrm{OH}) \mathrm{D}_{3}$ levels during the first and second trimesters of pregnancy could be associated with later risk of type 1 diabetes cannot be ruled out either.

\footnotetext{
Acknowledgements We are grateful to T. I. A. Sørensen, E. Hypponen and A. A. Vaag, the members of the 'D-tect' project Scientific Committee and Advisory Board, for their inputs while discussing the case-cohort study, as well as statisticians K. Raymond and L. H. Ängquist from the Institute of Preventive Medicine, Bispebjerg and Frederiksberg Hospital, for drawing the case-cohort study samples. We would also like to express our appreciation to B. Nørgaard-Pedersen and D. M. Hougaard from the Department of Congenital Disorders, Statens Serum Institute, for their support in the initial phases of this project. Furthermore, we thank S. Eising from the Copenhagen Diabetes Research Center (CPH-DIRECT) for collecting the DBS used in the case-control study.
}

Funding The case-cohort study is a part of the four-year project 'D-tect' funded by the Programme Commission on Health, Food, and Welfare under the Danish Council for Strategic research (grant number 0603-00453B). The case-control study was supported by a scholarship from Copenhagen University and by grants from Herlev University Hospital and the Capital Region of Denmark.

Duality of interest The authors declare that there is no conflict of interested associated with this manuscript.

Contribution statement RJ and SUT initiated the study, participated in its design and coordination, performed the statistical analyses and helped in the drafting and editing of the article. ASC and ML performed the $25(\mathrm{OH}) \mathrm{D}$ measurements on the DBS and helped in the drafting and editing of the article. PF was the statistician for the case-cohort study, supervised the statistical analyses, and helped in the drafting and editing of the article. CBP was the statistician for the case-control study, supervised the statistical analyses, and helped in the drafting and editing of the article. FP was the principal investigator for the study from which the case-control study retained its DBS, participated in the acquisition of data, and helped in editing of the article. LCT and AA initiated the case-control study, contributed to analysis and interpretation of data, and helped in editing of the article. JS participated in the design and coordination of the study, contributed to statistical analyses, and helped in drafting and editing of the article. BLH initiated the study, participated in its design and coordination, contributed to statistical analyses, and helped in drafting and editing of the article. All authors have read and approved the final version of the manuscript. RJ and SUT are the guarantors of this work and, as such, had full access to all the data in the study and take responsibility for the integrity of the data and the accuracy of the data analysis.

\section{References}

1. Atkinson MA, Eisenbarth GS, Michels AW (2014) Type 1 diabetes. Lancet 383:69-82

2. Svensson J, Lyngaae-Jorgensen A, Carstensen B, Simonsen LB, Mortensen HB (2009) Long-term trends in the incidence of type 1 diabetes in Denmark: the seasonal variation changes over time. Pediatr Diabetes 10:248-254

3. Groop L, Pociot F (2014) Genetics of diabetes-are we missing the genes or the disease? Mol Cell Endocrinol 382:726-739

4. Long MD, Sucheston-Campbell LE, Campbell MJ (2015) Vitamin $\mathrm{D}$ receptor and RXR in the post-genomic era. J Cell Physiol 230: 758-766

5. Vinkhuyzen AA, Eyles DW, Burne TH et al (2015) Prevalence and predictors of vitamin D deficiency based on maternal mid-gestation and neonatal cord bloods: the generation R study. J Steroid Biochem Mol Biol. doi:10.1016/j.jsbmb.2015.09.018

6. Giulietti A, Gysemans C, Stoffels K et al (2004) Vitamin D deficiency in early life accelerates type 1 diabetes in non-obese diabetic mice. Diabetologia 47:451-462

7. Cadario F, Savastio S, Pagliardini Vet al (2015) Vitamin D levels at birth and risk of type 1 diabetes in childhood: a case-control study. Acta Diabetol 52:1077-1081

8. Granfors M, Augustin H, Ludvigsson J, Brekke HK (2015) No association between use of multivitamin supplement containing vitamin D during pregnancy and risk of type 1 diabetes in the child. Pediatr Diabetes. doi:10.1111/pedi.12334 
9. Miettinen ME, Reinert L, Kinnunen L et al (2012) Serum 25hydroxyvitamin $\mathrm{D}$ level during early pregnancy and type 1 diabetes risk in the offspring. Diabetologia 55:1291-1294

10. Sorensen IM, Joner G, Jenum PA, Eskild A, Torjesen PA, Stene LC (2012) Maternal serum levels of 25-hydroxy-vitamin D during pregnancy and risk of type 1 diabetes in the offspring. Diabetes $61: 175-178$

11. Stene LC, Ulriksen J, Magnus P, Joner G (2000) Use of cod liver oil during pregnancy associated with lower risk of type I diabetes in the offspring. Diabetologia 43:1093-1098

12. Hollegaard MV, Grauholm J, Nielsen R, Grove J, Mandrup S, Hougaard DM (2013) Archived neonatal dried blood spot samples can be used for accurate whole genome and exome-targeted nextgeneration sequencing. Mol Genet Metab 110:65-72

13. Pedersen CB (2011) The Danish civil registration system. Scand J Public Health 39:22-25

14. Thygesen LC, Ersboll AK (2011) Danish population-based registers for public health and health-related welfare research: introduction to the supplement. Scand J Public Health 39:8-10

15. Eyles D, Anderson C, Ko P et al (2009) A sensitive LC/MS/MS assay of $25 \mathrm{OH}$ vitamin $\mathrm{D}_{3}$ and $25 \mathrm{OH}$ vitamin $\mathrm{D}_{2}$ in dried blood spots. Clin Chim Acta 403:145-151

16. Eyles DW, Morley R, Anderson C et al (2010) The utility of neonatal dried blood spots for the assessment of neonatal vitamin $\mathrm{D}$ status. Paediatr Perinat Epidemiol 24:303-308

17. Jacobsen R, Abrahamsen B, Bauerek M et al (2013) The influence of early exposure to vitamin $\mathrm{D}$ for development of diseases later in life. BMC Public Health 13:515

18. Eising S, Svensson J, Skogstrand K et al (2007) Type 1 diabetes risk analysis on dried blood spot samples from population-based newborns: design and feasibility of an unselected case-control study. Paediatr Perinat Epidemiol 21:507-517

19. Leek JT, Scharpf RB, Bravo HC et al (2010) Tackling the widespread and critical impact of batch effects in high-throughput data. Nat Rev Genet 11:733-739

20. McGrath JJ, Eyles DW, Pedersen CB et al (2010) Neonatal vitamin D status and risk of schizophrenia: a population-based case-control study. Arch Gen Psychiatry 67:889-894

21. Prentice RL (1986) A case-cohort design for epidemiologic cohort studies and disease prevention trials. Biometrika 73:1-11

22. Gray RJ (2009) Weighted analyses for cohort sampling designs. Lifetime Data Anal 15:24-40

23. Therneau TM, Grambsch PM (2000) Modeling survival data: extending the Cox model. Springer, New York

24. Cardwell CR, Carson DJ, Patterson CC (2005) Parental age at delivery, birth order, birth weight and gestational age are associated with the risk of childhood type 1 diabetes: a UK regional retrospective cohort study. Diabet Med 22:200-206

25. Haynes A, Bower C, Bulsara MK, Finn J, Jones TW, Davis EA (2007) Perinatal risk factors for childhood type 1 diabetes in Western Australia-a population-based study (1980-2002). Diabet Med 24:564-570
26. Jacobsen R, Hypponen E, Sorensen TI, Vaag AA, Heitmann BL (2015) Gestational and early infancy exposure to margarine fortified with vitamin D through a national Danish programme and the risk of type 1 diabetes: the D-Tect Study. PLoS One 10, e0128631

27. Wang Y, Jacobs EJ, McCullough ML et al (2009) Comparing methods for accounting for seasonal variability in a biomarker when only a single sample is available: insights from simulations based on serum 25-hydroxyvitamin D. Am J Epidemiol 170:88-94

28. Godang K, Froslie KF, Henriksen T, Qvigstad E, Bollerslev J (2014) Seasonal variation in maternal and umbilical cord $25(\mathrm{OH})$ vitamin $\mathrm{D}$ and their associations with neonatal adiposity. Eur J Endocrinol 170:609-617

29. Heath AK, Williamson EJ, Ebeling PR, Kvaskoff D, Eyles DW, English DR (2014) Measurements of 25-hydroxyvitamin D concentrations in archived dried blood spots are reliable and accurately reflect those in plasma. J Clin Endocrinol Metab 99:3319-3324

30. Magnus MC, Stene LC, Haberg SE et al (2013) Prospective study of maternal mid-pregnancy 25-hydroxyvitamin D level and early childhood respiratory disorders. Paediatr Perinat Epidemiol 27: $532-541$

31. Andersen LB, Jorgensen JS, Jensen TK et al (2015) Vitamin D insufficiency is associated with increased risk of first-trimester miscarriage in the Odense Child Cohort. Am J Clin Nutr 102:633-638

32. Haugen M, Brantsaeter AL, Alexander J, Meltzer HM (2008) Dietary supplements contribute substantially to the total nutrient intake in pregnant Norwegian women. Ann Nutr Metab 52:272280

33. Hypponen E, Laara E, Reunanen A, Jarvelin MR, Virtanen SM (2001) Intake of vitamin D and risk of type 1 diabetes: a birthcohort study. Lancet 358:1500-1503

34. Skrivarhaug T, Stene LC, Drivvoll AK, Strom H, Joner G (2014) Incidence of type 1 diabetes in Norway among children aged 0-14 years between 1989 and 2012: has the incidence stopped rising? Results from the Norwegian Childhood Diabetes Registry. Diabetologia 57:57-62

35. Cappelen J (2012) Denmark - DMI historical climate data collection 1768-2011 - with Danish abstracts. Danish Meteorological Institute, Copenhagen

36. Thuesen B, Husemoen L, Fenger M et al (2012) Determinants of vitamin $\mathrm{D}$ status in a general population of Danish adults. Bone 50: 605-610

37. Fetahu IS, Hobaus J, Kallay E (2014) Vitamin D and the epigenome. Front Physiol 5:164

38. Salle BL, Glorieux FH, Delvin EE (1988) Perinatal vitamin D metabolism. Biol Neonate 54:181-187

39. Jones KS, Assar S, Harnpanich D et al (2014) 25(OH)D2 half-life is shorter than 25(OH)D3 half-life and is influenced by DBP concentration and genotype. J Clin Endocrinol Metab 99:3373-3381

40. Fadel S, Sarzotti M (2000) Cellular immune responses in neonates. Int Rev Immunol 19:173-193 